\title{
Reconstituição paleoambiental do Lago Santa Ninha, Várzea do Lago Grande de Curuai, Pará, Brasil
}

\author{
Luciane Silva MOREIRA ${ }^{1}$, Patricia Florio MOREIRA-TURCQ², Renato Campello CORDEIRO³, Bruno Jean \\ TURCQ $^{4}$ \\ RESUMO
}

Este estudo teve por objetivo reconstituir as mudanças paleoambientais e paleohidrológicas no baixo Amazonas. Um testemunho de sedimento foi coletado no Lago Santa Ninha, na várzea do Lago Grande de Curuai, localizada na margem direita do Rio Amazonas a aproximadamente $850 \mathrm{~km}$ da foz. O teor de água, a granulometria, as dataçóes com carbono 14, os conteúdos de carbono orgânico e nitrogênio total e o isótopo estável do carbono $\left(\delta^{13} \mathrm{C}\right)$ foram utilizados para determinar os processos sedimentares a que o meio esteve submetido. $\mathrm{O}$ testemunho estudado possui $270 \mathrm{~cm}$ de comprimento que corresponde a um período de 5600 anos cal AP. Este estudo colocou em evidência diferentes ambientes sedimentares: na base do testemunho até 4900 anos cal AP há uma vegetação inundada que foi gradualmente substituida por bancos de gramíneas e por uma planicie com secas sazonais em 4000 anos cal AP até alcançar, desde 600 anos AP as condições atuais deste lago. Estas alterações podem ter ocorrido em decorrência de mudanças no ciclo hidrológico do Rio Amazonas que, por sua vez, também são reflexos de alterações climáticas.

PALAVRAS-CHAVES: paleohidrologia, paleoambientes, Amazônia, várzeas.

\section{Paleoenvironmental reconstruction of an Amazon floodplain lake, Lago Santa Ninha, Varzea do Lago Grande de Curuai, Pará, Brasil}

\section{ABSTRACT}

Physical, chemical and geochemical characteristics of lacustrine sediments were studied to reconstruct paleohydrologyical control on sedimentation in an Amazonian floodplain. A core was collected at the Lago Grande de Curuai floodplain, in the Santa Ninha Lake, located on the right margin of the Amazon River at $850 \mathrm{~km}$ of the estuary. Water content, granulometry, radiocarbon dating, organic carbon, nitrogen content and $\delta^{13} \mathrm{C}$ were used to characterize the sedimentary processes. The core is $270 \mathrm{~cm}$-long which corresponds to $5600 \mathrm{cal}$ years BP. The core points out different sedimentary environments: flooded vegetation at the base of the core till $4900 \mathrm{cal}$ years BP is substituted by grass banks changing to a floodplain encompassing prolonged annual dryness at $4000 \mathrm{cal}$ years BP. Since $600 \mathrm{cal}$ years BP, the present day Varzea Lake, permanently over flooded, has been installed.

KEY WORDS: paleohydrology, paleoenvironment, Amazonia, floodplain lakes.

\footnotetext{
1 Universidade Federal Fluminense, E-mail: lucianebiouff@yahoo.com.br

2 Institut de Recherche pour le Développement. E-mail: patricia.turcq@ird.fr

${ }^{3}$ Universidade Federal Fluminense, E-mail: rccordeiro@geoq.uff.br

${ }^{4}$ Institut de Recherche pour le Développement. E-mail: bruno.turcq@ird.fr
} 


\section{INTRODUÇÃO}

A Bacia Amazônica é a maior bacia fluvial do mundo, com área aproximada de seis milhōes de $\mathrm{Km}^{2}$ e descarga média anual que representa $20 \%$ de toda a água fluvial escoada para o oceano (Campos et al., 2001). Devido à sua extensa área, este sistema hidrográfico representa importante papel na modulação do clima e dos ciclos biogeoquímicos regionais e globais (Mayorga \& Aufdenkampe, 2002).

Devido à topografia plana (que não chega a exceder os $100 \mathrm{~m}$ acima do nível do mar), solos pouco drenados, grande variação sazonal da precipitação e altos níveis de pluviosidade (Junk, 1997), aproximadamente 17\% da Bacia Amazônica é permanente ou temporariamente inundada (Melack et al., 2004).

Estas áreas inundadas são localmente conhecidas como várzeas e ocupam uma área que varia entre $140000 \mathrm{~km}^{2} \mathrm{e}$ $500000 \mathrm{~km}^{2}$, dependendo da hidrologia do Rio (Martinez $\&$ Le Toan, 2007).

O balanço de massa de sedimento (Dunne et al., 1998; Maurice-Bourgoin et al., 2007) e de carbono orgânico (Moreira-Turcq et al., 2003) ao longo do Rio Amazonas, apresenta perda de material entre as cidades de Manaus e Obidos. Estes dados sugerem que os lagos de várzeas, que apresentam altas taxas de sedimentação, atuam como armadilhas de sedimentos e de carbono (Moreira-Turcq et $a l, 2004)$.

Os depósitos sedimentares registram as mudanças paleohidrológicas e paleoambientais dos últimos milênios (Behling \& Costa, 2000; Behling et al., 2001; Irion et al 2006) e, através destes registros, os estudos paleoclimáticos têm como objetivo detectar alteraçôes na vegetação e na dinâmica sedimentar de rios e lagos, identificando as mudanças ocorridas nos ecossistemas ao longo do tempo.

As reconstruções paleoclimáticas do Holoceno na Amazônia revelaram a existência de diferentes padróes climáticos nesta região. Durante o Holoceno Inferior e Médio o clima foi provavelmente mais seco e variável do que o registrado atualmente (Turcq et al., 2007). Entre 7000 e 4000 anos AP foram detectadas diversas ocorrências de paleoincêndios, através do estudo da deposição de carvão nos sedimentos, associados a eventos climáticos mais secos (Cordeiro et al., 2008, 1997, 1995; Turcq et al., 1998). Estes dados coincidem com o aumento nos níveis de $\mathrm{CO}_{2}$ revelados pelo testemunho de gelo de Taylor Dome, Antártida (Indermuhle et al., 1999).

Além desta evidência, outros dados também sugerem a ocorrência de clima seco durante o Holoceno. Análises de pólen revelaram a existência de fases secas na Amazônia Central entre 4000 e 3500 anos ${ }^{14} \mathrm{C}$ AP e 2100 e 700 anos
${ }^{14} \mathrm{C}$ AP (Absy, 1979) e no sul da Amazônia, entre 9000 e 3000 anos ${ }^{14} \mathrm{C}$ (Mayle et al., 2000).

Apesar destas fases mais secas, em outras regiōes foram constatadas condições mais úmidas, como no caso do Rio Curuá $(350 \mathrm{~km}$ de Belém, Pára). Behling e Costa (2000) observaram um aumento contínuo do nível da água entre 6000 e 2500 anos ${ }^{14} \mathrm{C}$ AP, interpretado como reflexo de um clima mais úmido. Irion et al (2006) também determinaram a ocorrência de uma fase mais úmida no baixo Tapajós, a partir de 4300 anos cal AP. No Lago Calado, Behling et al (2001) observaram uma diminuição de pólen de gramíneas em 4070 e 2010 anos cal AP, interpretados como aumento do nível da água nas enchentes e uma maior duração destas.

Para este estudo foi escolhido um Lago de várzea do Rio Amazonas, um ecossistema onde houve grande acúmulo de matéria orgânica durante os últimos 100 anos, (MoreiraTurcq et al., 2004) oriunda tanto do Rio Amazonas quanto da produção in situ, além do depósito de material sedimentar (Maurice-Bourgoin et al., 2007). Portanto, trata-se de um ambiente com grande potencial para a utilização de indicadores paleoambientais e paleohidrológicos, onde poucos trabalhos desta natureza foram realizados até o momento.

\section{ÁREA DE ESTUDO}

A região estudada é a do Lago Santa Ninha, situado na planície inundável conhecida como Várzea do Lago Grande de Curuai. Esta várzea é composta por uma série de lagos de águas brancas e pretas (Sioli, 1984), interconectados entre si e permanentemente conectados ao Rio Amazonas por meio de pequenos canais, representada pela figura 1 . Sua localização está entre as latitudes sul $01^{\circ} 50^{\prime} \mathrm{S}-02^{\circ} 15^{\prime} \mathrm{S}$ e longitude oeste $55^{\circ} 00^{\prime} \mathrm{W}-56^{\circ} 05^{\prime} \mathrm{W}$, na margem sul deste rio, a aproximadamente $850 \mathrm{~km}$ da sua desembocadura no oceano Atlântico.

O Lago Santa Ninha é de águas brancas, caracterizado por altos níveis de sedimentos em suspensão. Este lago está permanentemente conectado com o rio através de um canal, de pequena extensão (aproximadamente $3,5 \mathrm{~km}$ ), mas que possibilita a entrada constante de material fluvial, principalmente em época de altas águas (Amorin, 2006).

\section{MATERIAL E MÉTODOS}

O testemunho (TA14) de $2,70 \mathrm{~m}$ de comprimento e $8 \mathrm{~cm}$ de diâmetro foi utilizado para este estudo, as coordenadas do seu ponto de coleta são: $55^{\circ} 49^{\prime} 29.0^{\prime \prime}$ de longitude oeste e $2^{\circ} 07^{\prime} 31.2^{\prime \prime}$ de latitude sul, indicado na Figura 1. A escolha do local de coleta do TA14 foi baseada em um estudo sísmico realizado na Várzea de Curuai

Antes da abertura, o testemunho foi radiografado para a análise das estruturas sedimentares, que auxiliam na abertura e no fatiamento do mesmo. O testemunho foi aberto em seção 


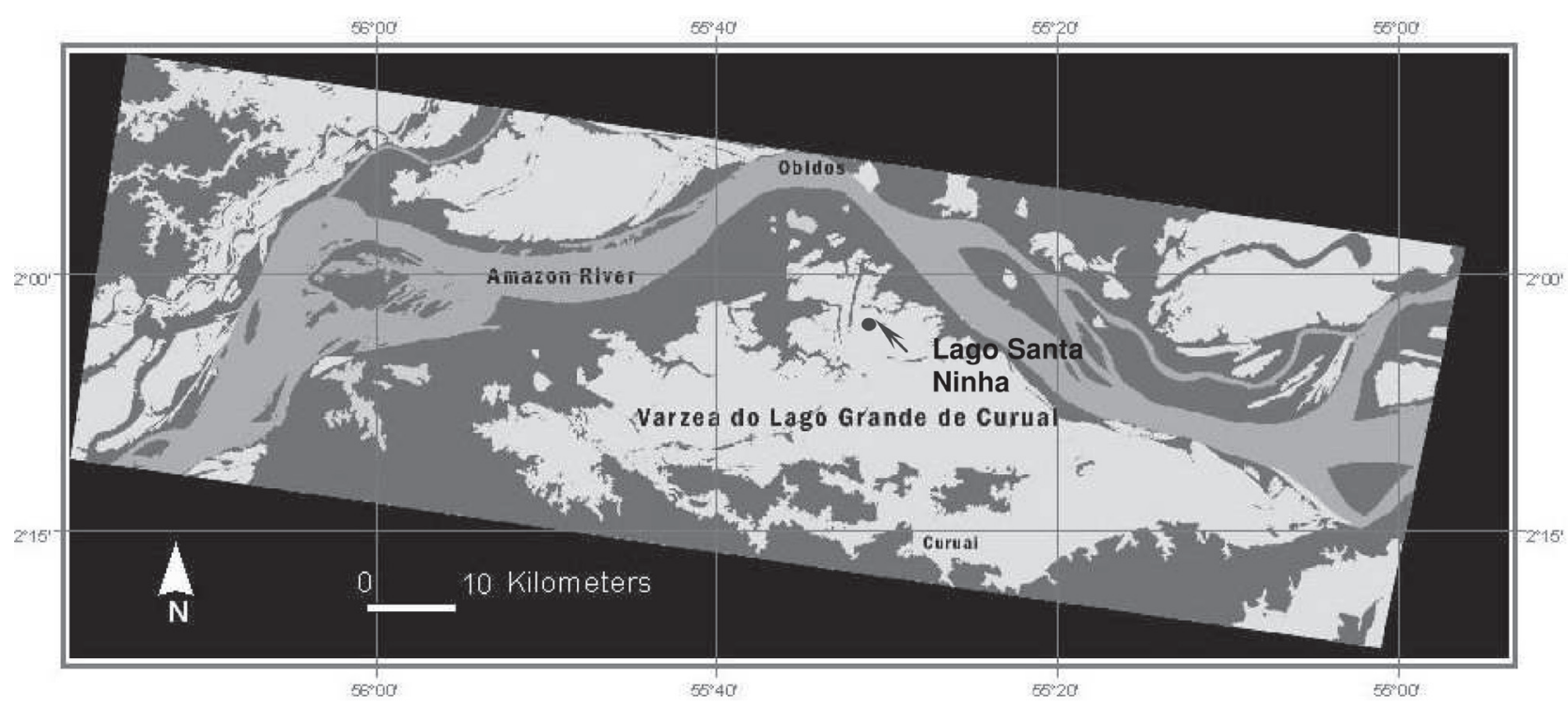

Figura 1- Localização da várzea do Lago Grande de Curuai, na margem direita do Rio Amazonas, com ênfase no Lago Santa Ninha local deste estudo, o ponto preto indica a posição de coleta do testemunho TA14.

transversal com auxílio de uma serra circular. O testemunho foi amostrado e cada amostra pesada ainda úmida para posterior secagem em estufa a $40^{\circ} \mathrm{C}$. O teor em água foi determinado, a cada centímetro, através da diferença entre o peso úmido e o peso seco. Doze amostras, ao longo do testemunho, foram selecionadas para datação por carbono $14\left({ }^{14} \mathrm{C}\right)$, estas foram secas em estufa à $50^{\circ} \mathrm{C}$ por 48 horas e analisadas por Espectrometria de Massa com Aceleradores (Accelerator Mass Spectrometry - AMS). As idades foram devidamente calibradas, com o auxílio do programa Calib 5.0.2 (disponível no site http://radiocarbon.pa.qub.ac.uk/calib/), passando a serem expressas em anos cal AP (Antes do Presente). A análise do fracionamento granulométrico foi determinada no Analisador de Partículas CILAS 1064. Foram analisadas 135 amostras do testemunho TA14, previamente tratadas a fim de eliminar a matéria orgânica presente. As amostras $(\mathrm{n}=135)$ destinadas a análise do teor de carbono orgânico total (COT) e nitrogênio total foram maceradas, pesadas e acondicionadas em cápsulas de estanho, após ataque acido $(\mathrm{HCl})$ para eliminar a presença de possíveis carbonatos, e os teores destes elementos foram estimados através de um analisador automático CHN. O isótopo estável de carbono $\left(\delta^{13} \mathrm{C}\right)$ foi determinado por espectrometria de massa acoplado ao CHN.

\section{RESULTADOS}

O testemunho TA14 foi dividido em 5 unidades litológicas, correspondendo a intervalos de variações de cor e de textura dos sedimentos, observados no momento da abertura, assim como mudanças das características sedimentares medidas posteriormente. Esta classificação está representada na tabela 1 .

Os resultados das dataçóes ${ }^{14} \mathrm{C}$ apresentados na Tabela 2 mostram que o TA14 apresentou idade de 5600 anos cal AP na profundidade de $270 \mathrm{~cm}$. Os primeiros $34 \mathrm{~cm}$ (unidade I) representam os últimos 600 anos cal AP. A profundidade de $34 \mathrm{~cm}$ foi caracterizada por um nível erosivo onde uma parte da sedimentação correspondendo a 1600 anos foi erodida. Abaixo deste nível erosivo a taxa de sedimentação manteve um valor médio de $0,05 \mathrm{~cm} \mathrm{ano}^{-1}$ e aumentou a partir da profundidade de $164 \mathrm{~cm}$ até a base do testemunho $(270$ $\mathrm{cm})$. Algumas idades estão invertidas, ou seja, idades maiores corresponderam a profundidades menores, como é o caso das profundidades $57-69 \mathrm{~cm}$ e $224-257 \mathrm{~cm}$. Estas inversōes

Tabela 1 - Descrição do testemunho TA14 segundo a tabela de Munssel e observações visuais apresentando as cinco unidades litológicas identificadas.

\begin{tabular}{lccc}
\hline $\begin{array}{l}\text { Unidades } \\
\text { litológicas }\end{array}$ & $\begin{array}{c}\text { Profundidade } \\
(\mathrm{cm})\end{array}$ & Descrição & Cor \\
\hline I & 0 a 34 & $\begin{array}{c}\text { camada com argila mais } \\
\text { rica em água }\end{array}$ & $\begin{array}{c}\text { Castanho } \\
\text { muito escuro } \\
\text { acinzentado }\end{array}$ \\
II & 34 a 125 & $\begin{array}{c}\text { argila compacta } \\
\text { variegado }\end{array}$ & $\begin{array}{c}\text { Castanho escuro } \\
\text { acinzentado }\end{array}$ \\
III & 125 a 164 & $\begin{array}{c}\text { argila silto arenosa } \\
\text { laminações escuras } \\
\text { contato erosivo em } \\
\text { 185 cm }\end{array}$ & Cinza escuro \\
IV & 164 a 199 & $\begin{array}{c}\text { Preto } \\
\text { laminações horizontais } \\
\text { com fragmentos } \\
\text { vegetais }\end{array}$ & Cinza escuro \\
V & 199 a 270 & \multicolumn{4}{c}{} \\
\hline
\end{tabular}


foram interpretadas como produto do retrabalhamento dos sedimentos antigos, consequentemente o modelo de idade em função da profundidade, representado pela Figura 2, somente considerou as idades mais jovens.

O teor de água do testemunho TA14 apresentou média de $50 \%$ na base e no topo (Figura 3). Porém, entre as profundidades 24 e $164 \mathrm{~cm}$ foi possível observar uma queda desse valor, chegando a $28 \%$. A partir desta profundidade, o teor de água começou a aumentar, até a base do testemunho.

$\mathrm{O}$ teor em argila apresentou esta mesma tendência, como já era de se esperar, visto que o material argiloso retém mais água do que o sedimento mais grosso. Conseqüentemente, também é justificável o fato de se encontrar mais matéria orgânica a partir da profundidade $164 \mathrm{~cm}$ até a base do testemunho, uma vez que a argila apresenta alta afinidade pelo material orgânico.

De forma geral, o perfil granulométrico do testemunho TA14 apresentou natureza silto-argilosa, com predominância de argila e silte fino (Figura 3). No entanto, algumas variações nas fraçōes de silte médio e grosso, foram observadas nas unidades III e IV. Estas duas unidades caracterizaram-se por apresentarem granulometria mais grossa (presença de silte fino, médio e grosso) com menor porcentagem de argila. A unidade IV $(166$ a $199 \mathrm{~cm})$ foi mais variável. Foi nesta unidade que observamos uma pequena fração arenosa, revelando rápida alteração do meio. A unidade V $(199$ a $270 \mathrm{~cm})$ foi a de granulometria mais fina de todo o testemunho, com média de $50 \%$ de argila e $46 \%$ de silte fino, caracterizada pela presença pouco significativa de silte mais grosso.

Ao longo do testemunho TA14 o COT (Figura 4) variou entre $0,13 \%$ a $21,5 \%$, que corresponderam as cinco diferentes unidades sedimentares descritas anteriormente. A unidade $\mathrm{V}$ foi a fase com maior concentração de COT, com média de $8,5 \%$, variando entre $4,2 \%$ e $21,5 \%$. Também foi neste

Tabela 2 - Idades ${ }^{14} \mathrm{C}$ (AMS), incerteza e idades calibradas do testemunho TA14.

\begin{tabular}{lcc}
\hline Profundidade $(\mathrm{cm})$ & Idade ${ }^{14} \mathrm{C}$ & Idade Calibrada (anos cal AP) \\
\hline $24-25$ & $525 \pm 69$ & 570 \\
$30-31$ & $590 \pm 30$ & 595 \\
$34-35$ & $2313 \pm 81$ & 2310 \\
$57-58$ & $3335 \pm 30$ & 3560 \\
$69-70$ & $3000 \pm 30$ & 3170 \\
$159-160$ & $4354 \pm 46$ & 4910 \\
$184-185$ & $4430 \pm 86$ & 5075 \\
$186-187$ & $4455 \pm 92$ & 5125 \\
$198-199$ & $4510 \pm 94$ & 5150 \\
$224-225$ & $4588 \pm 73$ & 5260 \\
$257-258$ & $4549 \pm 81$ & 5240 \\
$268-269$ & $4900 \pm 30$ & 5600 \\
\hline
\end{tabular}

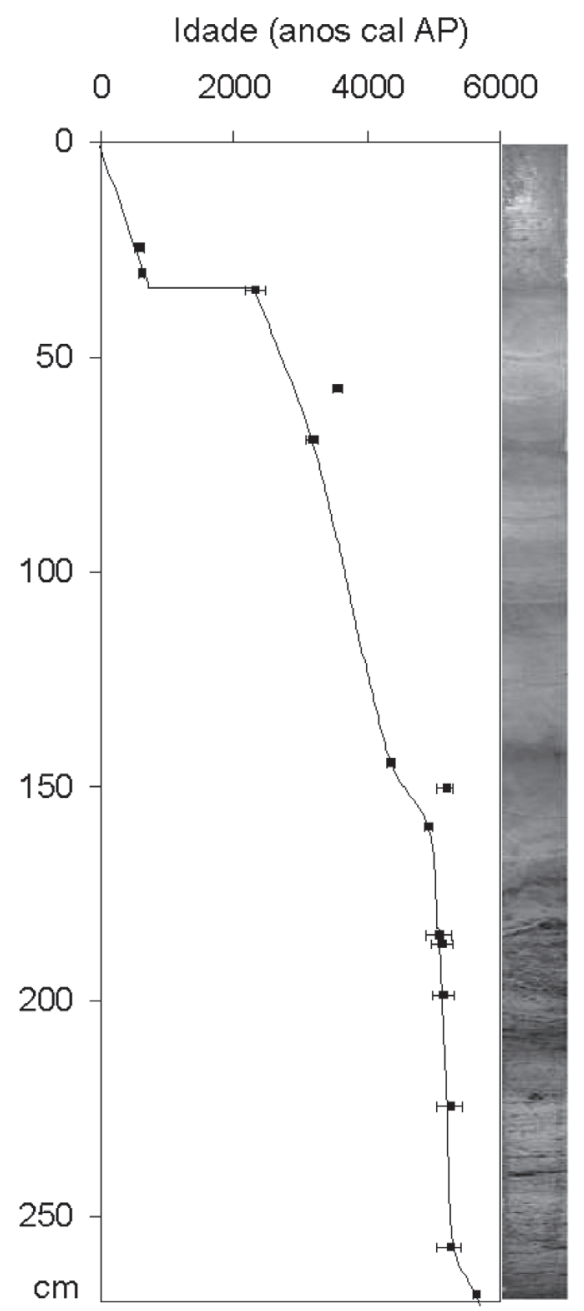

Figura 2 - Fotografia do testemunho TA14, Idades calibradas e modelo cronológico.

período que a granulometria foi a mais fina. Os níveis de COT diminuiram gradualmente após este período. Na unidade IV, o COT decresceu, com média de $7,6 \%$, e de $0,59 \%$ na unidade seguinte (III). Foi na unidade II que o COT apresentou os valores mais baixos de todo o perfil. Nesta unidade (II), os valores médios estão em torno de $0,2 \%$, variando entre $0,1 \%$ e $0,9 \%$. Já na unidade I o COT, média de 1,23\%, apresentou um leve aumento.

A relação $\mathrm{C} / \mathrm{N}$ nas unidades $\mathrm{V}$ e IV (Figura 4) apresentou os mais altos valores, com média de 22 e 18, respectivamente. A partir da unidade III (média de 5,73), o C/N sofreu acentuado decréscimo, apresentando seus valores mais baixos na unidade II $(2,36)$. Na fase mais recente (unidade I) ocorreu ligeiro aumento desta relação, com média de 5,4.

$\mathrm{O} \delta^{13} \mathrm{C}$ do testemunho TA14 variou entre -24 e $-31 \%$. Sendo que foi na unidade III que estes valores tornam-se menos negativos, apresentando um máximo de -24,15\%o., 


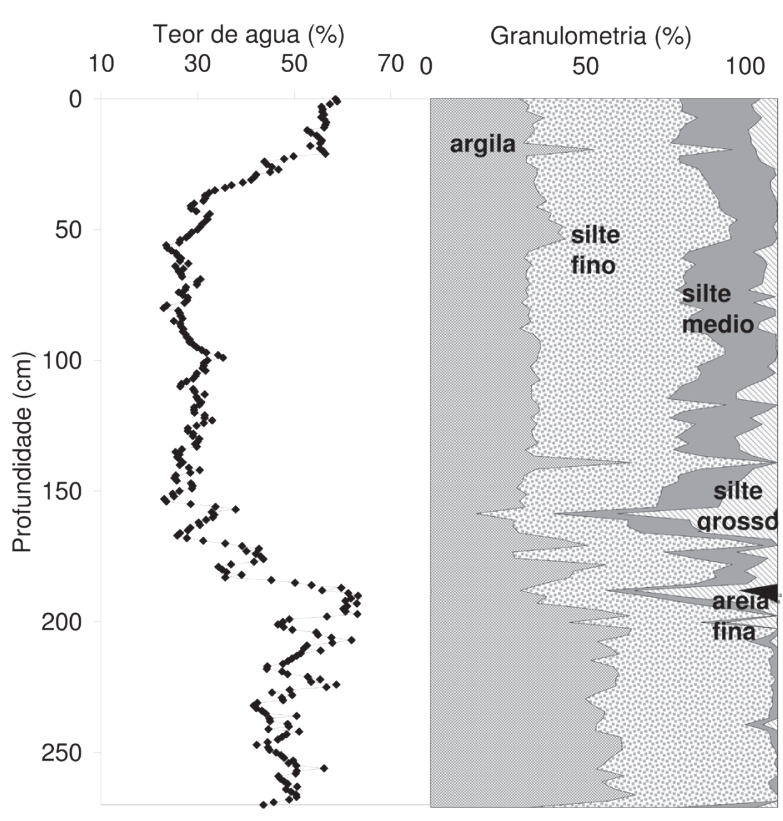

Figura 3 - Teor em água (\%) e as diferentes frações granulométricas (\%) do testemunho TA14.
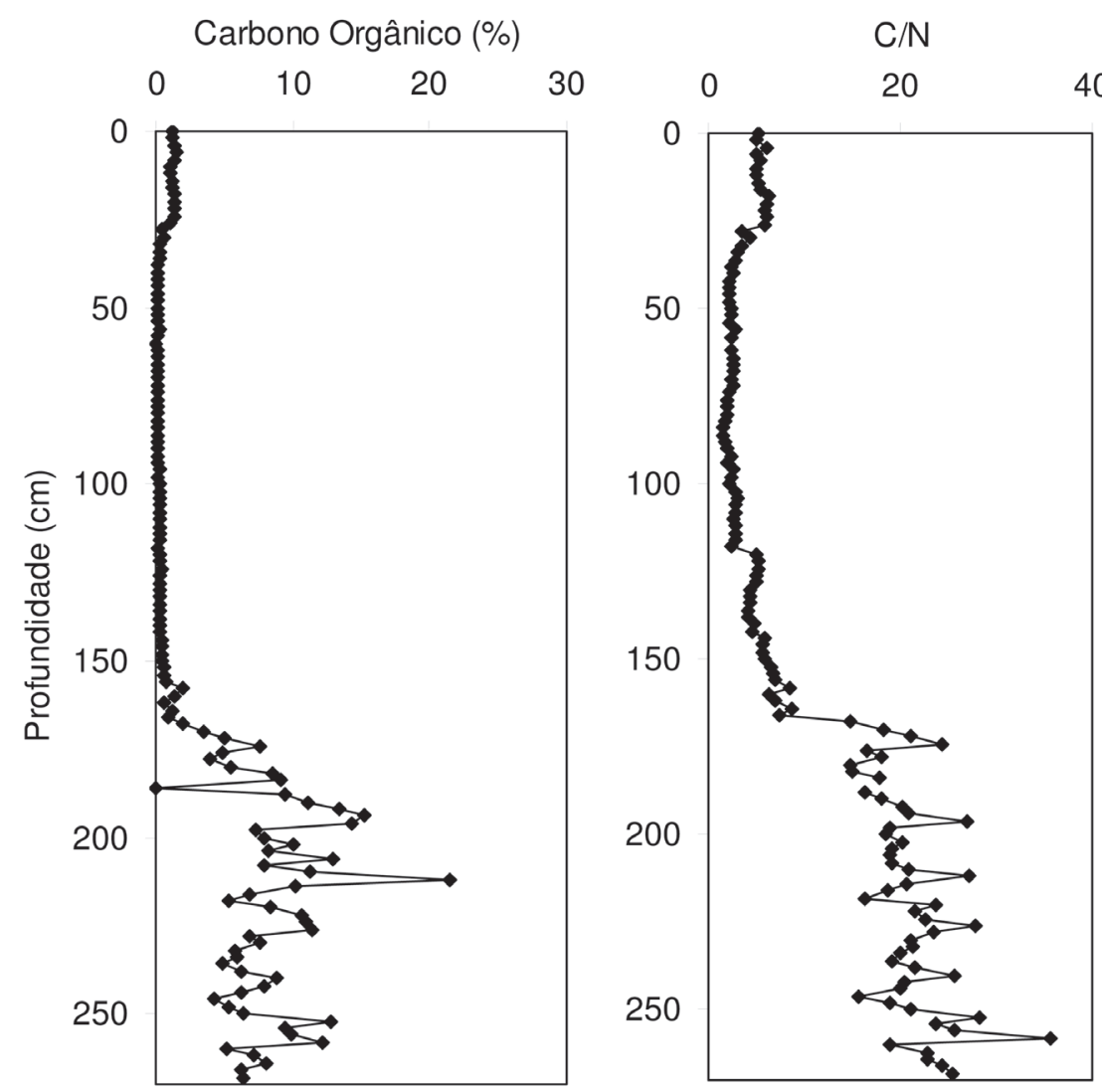

esta variação registra uma alteração no tipo de vegetação depositada no meio.

\section{DISCUSSÃO}

O testemunho TA14, segundo dados de datação por ${ }^{14} \mathrm{C}$, apresentou uma idade de 5600 anos cal AP. A análise das datações permitiu observar dois padrões de sedimentação distintos: a parte basal do testemunho foi caracterizada por uma taxa de sedimentação extremamente elevada $(0,34 \mathrm{~cm} /$ ano ) e a parte superior por uma taxa de sedimentação cinco vezes inferior a anterior.

$\mathrm{Na}$ parte basal do testemunho (de 164 à $270 \mathrm{~cm}$ que ocorreu entre 5600 e 5000 anos cal AP) observou-se alta taxa de sedimentação com média de $0,34 \mathrm{~cm} /$ ano. Esta unidade também foi caracterizada por alto teor de argila (média de $50 \%$ ) e alta concentração de COT (média de 8,5\%). Estas características sugerem que a hidrodinâmica desta região era bastante reduzida, sem muita correnteza, responsáveis pela sedimentação de material de granulometria mais fina. Ao mesmo tempo, é necessário, neste local, um ecosistema extremamente produtivo para manter as altas taxas de COT (geralmente observa-se uma diminuição do COT quando a taxa de sedimentação é alta, sustentada por aportes minerais

40

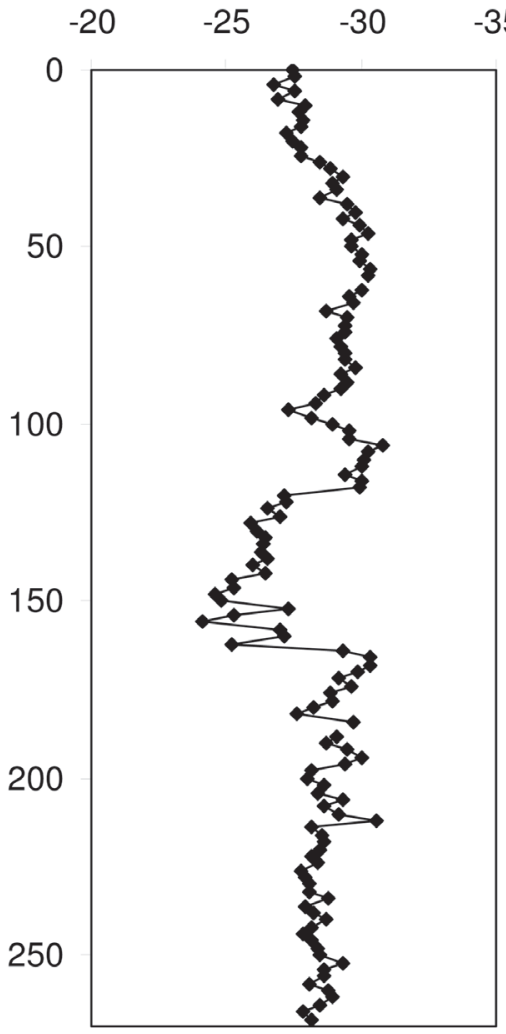

Figura 4 - Teor em carbono orgânico total (\%), relação C/N e $6{ }^{13} \mathrm{C}$ (\%) do testemunho TA14. 
que diluem o teor de COT no sedimento (Turcq et al., 2002; Turcq et al., 2007). A matéria orgânica na unidade $\mathrm{V}$ é caracterizada pela presença de restos vegetais, por alto valor $\mathrm{de} \mathrm{C} / \mathrm{N}(22)$ e por um $\delta^{13} \mathrm{C}$ bastante negativo (-28,5\%). Isso caracteriza uma matéria orgânica oriunda de vegetais superiores com ciclo fotossintético C3 (Martinelli et al.,1991; Meyers, 1994; Meyers, 2003). Podendo tratar-se de alta densidade de macrófitas ou até mesmo de uma floresta inundável. Esta última hipótese é reforçada pela observação, no microscópio, de grande quantidade de cutículas folhares.

O alto teor em COT do sedimento implica também uma boa preservação da matéria orgânica neste ambiente o que sugere fortemente a permanência da água no local, sem ficar exposto durante os períodos de águas baixas. Atualmente, no ponto de coleta do testemunho TA14, o nível médio das altas águas é de $550 \mathrm{~cm}$ enquanto o nível médio das águas baixas é de $50 \mathrm{~cm}$ durante um ciclo hidrológico (Bonnet et al., 2007, Martinez \& Le Toan, 2007). Mas deve-se considerar que a unidade V vai de 270 a $199 \mathrm{~cm}$ da coluna sedimentar, ou seja, o topo da unidade está situado $250 \mathrm{~cm}$ abaixo do nível mínimo atual das águas. Um nível de água, no periodo seco, de cerca de $250 \mathrm{~cm}$ (equivalente ao nível das águas baixas atuais) parece muito alto para manter a densa cobertura de macrófitas ou de uma floresta inundável, a não ser que houvesse poucas variaçōes entre o baixo e o alto nível da água da várzea nesta época. Portanto, em termos de paleohidrologia a unidade $\mathrm{V}$ apresenta o nível de águas baixas, provavelmente, mais baixo do que o atual, mas que não poderia ultrapassar menos de $250 \mathrm{~cm}$ (isso provocaria uma emersão dos sedimentos, inconsistente com a alta taxa de acumulação da matéria orgânica neste período). Por outro lado, a permanência de alta densidade de macrófitas ou até, de uma floresta inundada, implicaria que o nível máximo da água, durante a enchente, não poderia exceder cerca de $300 \mathrm{~cm}$ o nível das águas baixas, já que isso tornaria insustentável a permanência desta vegetação. Isso implica que o nível das águas altas em torno de $5000 \mathrm{cal}$ AP estaria entre 400 e $500 \mathrm{~cm}$ abaixo do nível atual.

A unidade IV (de 199 à $164 \mathrm{~cm}$ que ocorreu entre 5100 e $5000 \mathrm{cal} \mathrm{AP}$ ) representa uma fase de transição onde o teor de COT diminui, mas a taxa de sedimentação continua alta. Observa-se leve diminuição do $\mathrm{C} / \mathrm{N}$ e constância do $\delta^{13} \mathrm{C}$, que indicam a permanência da vegetação de macrófitas. Nesta fase, não foi mais observada grande quantidade de cutículas que marcariam a floresta inundada. Esta fase foi caracterizada por mudança da granulometria do sedimento com a presença marcante de areia fina na base da sequência e granulometria mais siltosa até o topo. Isso indica maior hidrodinâmica que poderia ser atribuída a um maior nível das enchentes.

A tendência granulométrica manteve-se na unidade III (de 164 à $125 \mathrm{~cm}$ que ocorreu entre 5000 e 4000 anos cal AP), mas ocorreu significativa diminuição da taxa de sedimentação e do COT. Os baixos valores de $\mathrm{C} / \mathrm{N}$ encontrados nesta fase e o $\delta^{13} \mathrm{C}$ menos negativo indicam mudança da natureza da matéria orgânica sedimentar. Estes dados sugerem a aparição das gramíneas na vegetação local. Isso pode ser devido a um aumento do nível das águas altas e provavelmente a uma maior influencia do Amazonas sobre o sistema, impossibilitando a permanência das macrófitas substituídas por gramíneas, mais adaptadas a variaçōes do nível da água.

A unidade II (de 125 à $34 \mathrm{~cm}$ que ocorreu entre 4000 e 2300 anos cal AP) foi caracterizada por concentrações de COT extremamente baixas (0,2\%) e baixa razão C/N $(2,36)$. Estes valores sugerem a ocorrência de repetidas secas, talvez anuais, propiciando a degradação da matéria orgânica (baixo COT).

A unidade I (de 34 à $0 \mathrm{~cm}$ que ocorreu entre 600 anos cal $\mathrm{AP}$ até os dias atuais) é caracterizada por teor de COT mais alto $(1,23 \%)$ que a unidade anterior, com baixa razão $\mathrm{C} / \mathrm{N}(5,4)$ devido a produção fitoplanctônica, principalmente durante as fases de enchente. Estas características correspondem ao ambiente atual da várzea. A transição para esta fase iniciouse desde $34 \mathrm{~cm}$ (2300 anos cal AP) com um aumento do conteúdo de argila no sedimento. Mas a sedimentação foi interrompida em $34 \mathrm{~cm}$, com um hiato de 2300 até 600 anos cal AP. A nitidez do contato irregular em $34 \mathrm{~cm}$ sugere evento erosivo anterior a $600 \mathrm{cal} \mathrm{AP}$. O aumento de argila e da produção fitoplanctônica na unidade superior pode corresponder a uma maior duração das enchentes que favoreceu a produção fitoplanctônica e limitou a exportação de sedimentos finos. A unidade I é caracterizada por uma taxa de sedimentação de $0,05 \mathrm{~cm} /$ ano.

No lago Calado, perto de Manacapuru no Solimões, Behling et al. (2001) observaram também uma diminuição do COT e do C/N em 4070 anos AP (correspondendo a 4550 anos cal AP). Esta diminuição é acompanhada de uma redução da proporção de pólen de gramíneas, substituídos por pólen da floresta de Igapó. Os autores interpretaram essa mudança como um aumento do nível da água nas enchentes e uma maior duração destas. Um nível de enchente também superior ao ciclo hidrológico atual é registrado em $2010 \mathrm{cal}$ AP. Esta data corresponde ao hiato no testemunho TA14.

Irion et al (2006) observaram no baixo Tapajós, onde a sedimentação é praticamente do tipo lacustre, mudanças de sedimentação menos marcantes do que no testemunho TA14. Uma mudança importante ocorreu em $4300 \mathrm{cal} \mathrm{AP} \mathrm{associada}$ a diminuição da taxa de sedimentação de 3,8 para $2,4 \mathrm{~mm}$ por ano. Os autores interpretaram essa mudança como diminuição do fluxo do rio ou fluxo mais constante. Isso não corresponde muito bem às conclusóes deste presente trabalho ou às de Behling et al.(2001), que descrevem aumento das enchentes nos últimos 5000 anos. O pólen do testemunho do Tapajós (Irion et al., 2006) indicou redução da proporção de Cecropia 
de 40 para 15\% em 4300 anos cal AP, interpretada como redução da frequiência e/ou da intensidade dos eventos de seca. Este quadro é de um clima que tornou-se mais úmido após 4300 anos cal AP, estando de acordo com as interpretaçôes deste presente trabalho.

\section{CONCLUSÕES}

A análise do material sedimentar do testemunho TA14 revelou que, nos últimos 5700 anos, ocorreram mudanças paleohidrológicas e paleoambientais nesta região, que alteraram o tipo de vegetação e a dinâmica sedimentar do lago.

Os parâmetros analisados mostraram cinco fases de sedimentação: de 5600 a 5100 anos cal AP observou-se um clima mais úmido, com variaçôes do ciclo hidrológico menos intensificadas, o que permitia o desenvolvimento de uma floresta inundável. Entre 5100 e 5000 anos cal AP o tipo de vegetação não apresentou modificações significativas, porem existem indícios de maior ocorrência de enchentes, assim como observado por outros autores em diferentes regiōes amazônicas (Behling et al., 2001; Irion et al., 2006).

Entre 5000 e 4000 anos cal AP, é observada uma clara alteração na composição biótica do meio, com valores de $\delta^{13} \mathrm{C}$ típicos de gramíneas, que são indicativos de um clima mais variável. Entre 4000 e 2300 anos cal AP observa-se a ocorrência de repetidas secas. Esta fase é precedida por um longo hiato, que ocorreu entre 2300 anos e 600 anos cal AP.

Após este período mais seco, os níveis de cheias foram se estabilizando até atingir as condiçôes atuais do lago, num processo que vem ocorrendo desde 600 anos cal AP. Durante este período é observado uma ativa produção fitoplanctônica, como é encontrado atualmente.

Estes dados revelam a influência que as modificaçōes no ciclo hidrológico do rio exercem nos ecossistemas de várzea e demonstram que as enchentes no passado eram inferiores as observadas atualmente. Como o clima é um dos principais fatores que controlam o comportamento dos rios, alteraçōes na sua dinâmica fluvial indicam mudanças climáticas ocorridas na região. Portanto, as alteraçōes observadas na dinâmica do lago são reflexos de mudanças climáticas que ocorreram neste local durante os últimos 5600 anos cal AP.

\section{AGRADECIMENTOS}

Os autores agradecem a ajuda técnica da CPRM (Companhia de Pesquisa em Recursos Minerais) durante a campanha de campo para a coleta do testemunho. L. Moreira é bolsista de mestrado da CAPES. Este estudo faz parte de um projeto de Cooperação Internacional entre o CNPq e o IRD (Institut de Recherche pour le Développement - França) e é realizado pelo Programa Hybam.

\section{BIBLIOGRAFIA CITADA}

Absy, M.L. A palynological study of Holocene sediments in the Amazon basin.1979. 86 f. Tese de doutorado. University of Amsterdam.

Amorim, M. A. Estudo da sedimentação recente na Várzea do Lago Grande do Curuai, Pará, Brasil. Niterói, 2006. 150 f. Dissertação (mestrado). Departamento de Geoquímica, Universidade Federal Fluminense.

Behling, H.; Costa, L.D. 2000. Holocene environmental changes from the Rio Curuá record in the Caxiuana region, Eastern Amazon Basin. Quaternary Research, 53: 369-377.

Behling, H.; Keim, G.; Irion, G.; Junk, W.; Nunes de Mello, J. 2001. Holocene environmental changes in the Central Amazon Basin inferred from Lago Calado (Brazil). Palaeogeography, Palaeoclimatology, Palaeoecology, 173: 87-101.

Bonnet, M.P.; Barroux, G.; Martinez, J.M.; Seyler, F.; MoreiraTurcq, P.; Cochonneau, G.; Melack, J.M.; Boaventura, G.; Maurice-Bourgoin, L.; León, J.G.; Roux, E.; Calmant, S.; Guyot, J.L.; Seyler, P. 2007. Flooding hydrology in an Amazonian floodplain lake (Lago Grande de Curuai). Journal of Hydrology (doi:10.1016/j.jhydrol.2007.10.055).

Campos, I. D. O.; Mercier, F.; Maheu, C.; Cochonneau, G.; Kosuth, P.;Blitzkow, D.; Cazenave, A. 2001.Temporal variations of river basin waters from Topex/Poseidon satellite altimetry. Application to the Amazon basin. Earth and Planetary Sciences 333: 633-643.

Cordeiro, R. C.; Turcq, B.; Suguio, K.; Silva, A.O.; Sifeddine, A.; Volkmer-Ribeiro, C. 2008. Holocene fires in east Amazonia (Carajás), new evidences, chronology and relation with paleoclimate. Global and Planetary Change, 61: 49-62.

Cordeiro, R.C.; Turcq, B.; Oliveira da Silva, A.; Suguio, K. 1997. Holocene environmental changes in Carajás region (Pará, Brazil) recorded by lacustrine deposits. Verh. Internat. Verein. Limnol, 26: 814-817.

Dunne, T.; Mertes, L.A.; Meade, R.H.; Richey, J.E.; Forsberg, B.R.. 1998. Exchanges of sediment between the floodplain and channel of the Amazon River in Brazil. GSA Bulletin 110(4): 450-467.

Indermuhle, A.; Stocker, T. F.; Joos, F.; Fischer, H.; Smith, H. J.; Wahlen, M.; Deck, B.; Mastroianni, D.; Tschumi, J.; Blunier, T.; Meyer, R.; Stauffer, B.1999. Holocene carbon-cycle dynamics based on CO2 trapped in ice at Taylor Dome, Antarctica. Nature, 398:121-126

Irion, G.; Bush, M.B.; Nunes de Mello, J.A.; Stüben, D.; Neumann, T.; Müller, G.; Morais, J.A.; Junk, W.. 2006. A multiproxy palaeoecological record of Holocene lake sediments from the Rio Tapajós, eastern Amazonia. Palaeogeography, Palaeoclimatology, Palaeoecology, 240: 523-535.

Junk, W.J. 1997. General aspects of floodplain ecology with special reference to amazonian floodplains. In: Junk W.J. (ed.) The Central Amazon floodplain: ecology of a pulsing system, Berlin, Springer. p. 3-20.

Ledru, M.-P.; Bertaux, J.; Sifeddine, A.; Suguio, K. 1998. Absence of last glacial maximum records in lowland tropical forests. Quaternary Research, 49(2): 233-237. 
Martinelli, L.A.; Devol, A.H.; Victoria, R.L.; Richey, J.E. 1991. Stable carbon isotope variation in C3 and C4 plants along the Amazon River. Nature 353, 57-59.

Martinez, J.M. ; Le Toan, T. 2007. Mapping of flood dynamics and vegetation spatial distribution in the Amazon flooplain using multitemporal SAR data. Remote Sensing Environ., 108 (3), 209-233.

Maurice-Bourgoin, L.; Bonnet, M.-P.; Martinez, J.-M.; Kosuth, P.; Cochonneau, G.; Moreira-Turcq, P.; Guyot, J.-L.; Vauchel, P.; Filizola, N.; Seyler, P.. 2007. Temporal dynamics of water and sediment exchanges between the Curuaí floodplain and the Amazon River, Brazil. Journal of Hydrology, 335: 140-156.

Mayle, F. E.; Burbridge, R.; Killeen, T. J. 2000. Millennial-Scale Dynamics of Southern Amazonian Rain Forests. Science, 290: 2291-2294.

Mayorga, E.; Aufdenkampe, A. K. 2002. Processing of bioactive elements in the Amazon river system. The Ecohydrology of South American Rivers and Wetlands, 6: 1-24.

Melack, J. M. ; Hess, L. L. ; Gastil, M. ; Forsberg, B. R. ; Hamilton, S. K. ; LIMA, I. B. T. ; Novo, E. M. L. M. 2004 . Regionalization of methane emissions in the Amazon basin with microwave remote sensing. Global Change Biology, 10: 1-15.

Meyers, P.A. 1994. Preservation of elemental and isotopic source identification of sedimentary organic matter. Chemical Geology, 114: 289-302.

Meyers, P.A.. 2003. Applications of organic geochemistry to paleolimnological reconstructions: a summary of examples from the Laurentian Great Lakes. Organic Geochemistry, 34: 261-289.
Moreira-Turcq, P.; Jouanneau, J. M.; Turcq, B.; Seyler, P.; Weber, O.; Guyot, J. L. 2004. Carbon sedimentation at Lago Grande de Curuai, a floodplain Lake in the low Amazon Region: insights into sedimentation rates. Palaeogeography, Palaeoclimatology, Palaeoecology, 214(1-2): 27-40.

Sioli, H.1984. The Amazon and its main affluents: hydrography, morphology of the river courses, and river types. In: SIOLI, H. (ed) The Amazon - Limnology and ladscape ecology of a mighty tropical river and its basin. Monographiae Biologicae. Junk, Dordrecht, p. 127-165.

Suguio, K.; Bigarella, J. J. Ambiente fluvial. Curitiba: Editora Universidade Federal do Paraná, 1979. 189 p.

Turcq, B.; Suguio, K.; Martin, L.; Flexor, J.M. Registros milenares nos sedimentos dos lagos da serra de Carajás.1998. Ciência Hoje, 16 (93): 31-35.

Turcq, B.; Albuquerque, A.L.S.; Cordeiro, R.C.; Sifeddine, A.; Simoes Filho, F.F.L.; Souza, A.G.; Abrao, J.J; Oliveira, F.B.L.; Silva, A.O.; Capitaneo, J.. 2002. Accumulation of organic carbon in five Brazilian lakes during the Holocene. Sedimentary Geology, 148 (1-2): 319-342.

Turcq, B.; Braconnot, P.; Cordeiro, R. C.; Sifedinne, A.; Silva Dias, P. L.; Abrão, J.J.; Jorgetti, T.; Lima Da Costa, R.; Simões Filho, F.F. 2007. Mudanças paleoclimáticas da Amazônia no holoceno. Ciência e Ambiente, 34: 69-96.

Recebido em 19/12/2007

Aceito em 15/04/2009 